\title{
Computers in Education of Children with Intellectual and Related Developmental Disorders
}

\author{
doi:10.3991/ijet.v5s2.1246 \\ V. Kirinić, V. Vidaček-Hainš, A. Kovačić \\ University of Zagreb, Varaždin, Croatia
}

\begin{abstract}
Children suffering from intellectual deficiency and disorders arising from such a condition tend to be provided with a specific form of education, depending on the deficiency type and degree. Apart from the disorder itself, the acquisition of knowledge, skills and learning habits depends on the children's motivation for learning, as well as the accessibility of the computer. When used in conformance with pedagogical, didactic and clinical standards, the computer as an educational aid may prove helpful for education and training of children with developmental disorders. Using computers also enables communication and fosters communication skills resulting in the development of self-confidence.
\end{abstract}

Index Terms-educational technology, intellectual deficiency, special education

\section{INTRODUCTION}

These days increasingly more attention is given to the education and training of persons suffering from disability, so as to enable them to acquire specific skills and knowledge and thus integrate more easily into the society. Disability is a lack of ability relative to a personal or group standard or norm that inhibits the individual from performing various activities, which in turn calls for specific modes of adaptation. There are several classifications of disorders. From the most general point of view, they can be divided into physical impairment, sensory impairment, cognitive or intellectual impairment, mental disorder (also known as psychiatric or psychosocial disability) and various other types of chronic disease. Each of these categories requires a specific approach in diagnostics, therapy and, consequently, education and training. A detailed classification of diseases is comprised within the International Classification of Diseases, Injuries and Causes of Death, adopted by the World Health Organization [1]. In particular, the classification of mental disorders is contained within the DSM-IV classification, that is, the "Diagnostic and Statistical Manual of Mental Disorders, Fourth Edition (DSM-IV)", issued by the American Psychiatric Association [2]. Within the classification of mental disorders, the area of mental retardation stands out, owing to the distinct nature of disorders that tend to imply other retardation-related disorders and limitations. The most severe type of mental retardation is profound mental retardation, which, in order of severity, is followed by severe mental retardation, then moderate mental retardation, mild mental retardation and borderline intellectual functioning, respectively. The degree of mental retarda- tion is determined in relation to the IQ obtained by measurement. Other terms for this condition include "mental handicap", "intellectual deficit" or "special needs".

The main objective of this paper is to provide an overview of examples of good practice in the ways in which persons with developmental disability use the computer. Furthermore, its objective is to highlight the beneficial effects of the process of motivation and socialization when these processes are aided by the computer, compared to conventional forms of learning without the use of computers. The paper also deals with the issue of curriculum adaptation as a prerequisite in catering for individual needs of students with disabilities.

\section{INDIVIDUAL NEEDS AND CURRICULUM SPECIFICITIES}

Depending of the type and degree of disability, the age group and the preserved skills and motivation, a person with developmental disorders can be included into the process of training and education in accordance with a modified curriculum. In planning such an adopted curriculum it is necessary to take into consideration specific aspects of individual diagnoses, which serve as a basis for organizing small groups of students supervised by experts, typically special teachers, rehabilitation specialists, speech therapists, psychologists, etc. Apart from the traditional pedagogical and instructional practices, contemporary information and communications technology makes it possible to use the computer in the education of persons with disability. Advantages of such an approach are, primarily, achieving a higher level of motivation of persons with disability, improvement of communication, possibility to acquire certain skills for independent living in controlled conditions by using simulation models based on problem situations, etc. In the broadest sense, the computer can be used in the process of rehabilitation, in diagnostics, as well as in evaluating the results of the educational process.

Regardless of vast possibilities provided by the use of computer in contemporary educational curricula, individual needs of persons with developmental disorders, arising from their respective diagnosis, specific developmental disorders, acquired skills, motivation and environmental factors should by no means be neglected. While choosing the mode of education and appropriate curriculum, a multilevel decision-making model which takes into consideration the unique needs of learners with mental retardation [3] has proved helpful indeed. 


\section{ASSISTIVE TECHNOLOGY}

Assistive technology (AT) can play a major role in overcoming the barriers that persons with developmental disorders have to face. More concretely, assistive technology includes assistive, adaptive, and rehabilitative devices for people with disabilities. By means of assistive technology disabled people can achieve independence in executing routine tasks.

The Individuals with Disabilities Education Act Amendments of 1997 define the assistive technology device as "any item, piece of equipment, or product system, whether acquired commercially off the shelf, modified, or customized, that is used to increase, maintain, or improve the functional capabilities of a child with a disability" [4].

Assistive technology can be categorized as follows [5]:

- AT for vision (helping students who are blind or have low vision), ranging from eyeglasses, large-print books, books on tape, ..., to Braille stylus, Braille writer, Braille translation software, Braille printer and computer with speech output or feedback, operating system accessibility options, etc.;

- AT for communication (helping students who are unintelligible, have no or very little verbal skills, or have limited language proficiency), ranging from pictures, photographs, word cards, ..., to simple voiceoutput devices, text-to-voice and voice-to-text software, talking word processing with writing support, word prediction, abbreviation, or expansion options to reduce keystrokes, software that allows communication via pictures and symbols, etc.;

- AT for access (helping students who have difficulties in accessing communication, learning tools, or engaging in classroom or home activities), e.g. head pointers, joysticks, adapted mouse, typewriter, book holders, onscreen keyboards, voice input or output devices, voice-recognition software, eye-controlled computer-input devices, etc.;

- AT for hearing (helping students who are deaf or hard-of-hearing), e.g. hearing aids, pictures, photographs, vibrotactile systems, etc.;

- AT for learning and studying (helping students with high-incidence disabilities - learning, behaviour, or cognitive disabilities), e.g. Post-It notes, picture schedules, written schedules, social stories, graphic organizers to visually help in developing and structuring ideas, electronic organizers or reminders, etc.

The above-mentioned technologies reveal that there is a growing tendency for functions of certain assistive technology devices to be fully or partially realized by means of computers, either through hardware or software.

\section{COMPUTERS IN EDUCATION OF CHILDREN WITH MENTAL RETARDATION}

\section{A. Technology to support education}

The categorization of ICT in education by the ways in which it is used in teaching, devised by Means [6], is referred to in the paper by Florian [7]. According to that categorization, ICT can be used to tutor or to explore, can be applied as a tool, used to communicate, and also used for assessment and management purposes.
Means claims that "tutor programs represent a longstanding type of teaching with technology" which "help teachers individualize learning and learners to work at their own pace". This is known as computer-assisted instruction (CAI). CAI programs were used in the way that "learners worked individually at a computer on tasks that tended to emphasize drill and practice, or the enforcement of previously taught skills". In this sense, the use of computer was grounded on the behavioural theory of learning.

Furthermore, the computer is used to build exploratory learning environments allowing "pupils to interact with the material and have more control over their learning" and "emphasize exploration as opposed to drill and practice or the reinforcement of skills and knowledge". In this sense, it represents the constructivist theory of learning.

In addition, when applied as a tool, ICT emphasizes technical skills needed outside the learning environment. As such, it represents a prerequisite for other types of learning with technology, and is thus essential for everyday life beyond school.

The computer used as an assistive technology device helps pupils communicate too (e.g. voice synthesizers and voice recognition software). "Many of the symbol communication systems used by some pupils with special education needs (SEN) are supported by software programs to enable pupils, for example, to write and e-mail" [7].

Another worthwhile use of ICT is that of tools for assessment - in diagnosing the nature of the child's learning difficulty. By using ICT for that purpose, the labourintensive procedures involved are executed more effectively.

Finally, teachers of students with SEN are required to develop individual education plans (IEPs) adapted to each student. In that case, teachers can use ICT as a management tool since "a number of software programs designed to help them manage the day-to-day responsibilities of providing for pupils with SEN have been developed".

\section{B. Motivation}

Compared to traditional education, computer-aided education has largely proved to be more effective and efficient, primarily owing to additional motivation enhanced by the interaction with the computer.

Accordingly, the use of computers has also proved beneficial in education of children and adolescents with mental retardation and attention deficits. Research has shown that, whereas such students require more training in preparing for discriminative sensory perceptive abilities tests than their younger counterparts of the same mental age - mainly due to fluctuating attention - the application of touch-screen technology enhances motivation and helps such students proceed with the task. Computer-aided education tends to attract their attention more than conventional pen-and-paper tasks [8].

Dube and McIlvane [9] emphasize the motivational component in terms of the importance of reinforcement of respondents with mental retardation engaged in discriminative perceptive abilities tests on the computer. The authors have confirmed that it is extremely important that each instance of positive behaviour is followed by reinforcement in regular intervals. Occasional rewards, on the contrary, did not result in desired behaviour related to learning and test execution. 
In addition, the motivation for using the computer has proved to have effect on learning success itself. Children with developmental disabilities using the computer in doing sorting and matching tasks achieved better results provided they had been given additional training [10].

\section{Social component}

Apart from motivation, using computers in the education of persons with developmental disorders is important as it contains the social interaction component. For instance, parents and teachers of children with attention deficit hyperactivity disorder (ADHD) have noticed that computer-aided collaborative work was fairly effective not only in educational terms but also in developing social skills. The reason for this may be that children who are normally not so popular among their peers are likely to be better accepted by their peers on account of their computer skills [11].

The process of acquiring knowledge and thinking skills in computer-assisted training is focused on defining learning strategies and outcomes. Using computers in education can help persons with mental retardation to better understand particular parts of task structure, while facilitating their interaction with the teacher [12].

\section{Simulation of everyday situations}

One of the goals of special education is the acquisition of specific independent living skills. Standen and Brown [13] give an overview of using virtual reality in rehabilitation of persons with intellectual disabilities, both children and adults. Their paper comprises studies utilizing virtual technology to promote skills for independent living: grocery shopping, preparing food, orientation, road safety and manufacturing skills. Persons with intellectual disability aged 7-46 were included in the studies.

Computer simulation was used with adult persons with mental retardation acquiring money management skills. In particular, respondents were trained to use voice commands in giving instructions to the computer regarding the use of their bank account. Namely, it has been established that money management presents a critical area of acquiring independent living skills in adults with mental retardation. However, simulation software is not only a useful aid in helping persons with mental retardation acquire practical routine tasks. In a less direct sense, with additional training, using such software enables easier integration of adults with mental retardation into the community [14].

\section{E. Reading and writing}

The computer has been established as a useful tool for helping children enhance their linguistic abilities. Compared with human teaching, the computer has obvious advantages such as endless repetition, direct feedback, and the fact that children do not feel judged [15].

Several studies reveal significant gains in reading with the help of CAI programs [16] and the effectiveness of a computer program in teaching sight word recognition to young children with developmental disabilities [17]. Namely, initial learning of reading and writing in children with developmental disorders is a slow and long-lasting process which does not necessarily yield desired results, not only due to intellectual limitations, but also to students' low motivational level.
Lee and Vail [17] claim that the software designed for learning sight words and word recognition in initial learning of reading and writing is one of examples of good practice in the education of children with developmental disability. Children learned to use this software by following reading instructions. Considering that the software itself is interactive and requires active participation of respondents, children using it may be additionally motivated for its application. The results achieved in learning to read were in certain cases better than those yielded in conventional face-to-face instruction.

Howell et al. [18] also did research into the effects of using a software-based early reading program with early school children suffering from reading failure. Along with conventional methods of instruction in children's direct interaction with teachers, the software for initial learning of reading and writing was experimentally implemented. In the course of the research, balanced reading instruction was used. Children were involved in word identification tasks. The results show that children with developmental disorders and specific reading failure have statistically significantly lower achievement in reading in various situations and guided by varied reading instructions. In addition, such children are significantly slower than children without reading failure. However, results also show that children with developmental disorders and specific reading failure, when exposed to a combination of traditional methods of instruction and computer-aided instruction, are more successful compared with other children with specific developmental disorders taught exclusively in the traditional way without using the computer.

In addition to the impact of software-based early reading program upon the acquisition of reading, it has also been proved that other computer-aided learning methods, such as Computer-Based Cognitive Mapping, can have effects on reading comprehension for students with emotional behaviour disorders [19].

On the other hand, the effectiveness of the acquisition of writing - or, sometimes, spelling in particular - in children with mental disabilities can also be enhanced by using specialized software. Word Prediction Software, for example, has proved to impact written output of students with physical disabilities, as it resulted in higher percentages of legible words, correctly spelled words, and correct word sequences; and in longer mean lengths of consecutive correct word sequences than handwriting [20].

\section{OVERVIEW OF SOFTWARE TO HELP SPECIAL EDUCATION}

\section{A. SymWriter}

Communicate: SymWriter from Widget [21] is a tool for simple word and symbol processing which enables users to see the meaning of words as they write. Nonkeyboard users can write by selecting symbols from grids and buttons, so it can support people who cannot write text but that can write using symbols, and text writers with a limited vocabulary. There is a speech feedback to be used to speak individual letters, words and sentences as they are created, or to hear whole documents read back. The pictorial spell checker helps users understand the meaning of selected words by illustrating them with symbols, whether or not symbols are used in the finished document [21]. The main strength of the software is the 
usage of new "smart symbolising" technology, enabling more accurate symbolisation of text, with less need for manual corrections.

The software is intended for adult users to increase the involvement and motivation by creating visual strategies, such as behaviour charts and signage, or organisational tools, such as personal plans and shopping lists [21]. There is a range of resources to support Communicate: SymWriter, providing complementary screen-based activities and building an educational environment (setting). The software producer [21] emphasizes the possibility that activities can be designed specifically to support users with Alternative and Augmentative Communication (AAC) devices or users with physical difficulties who use switches.

\section{B. BoardMaker}

The Boardmaker Software Family [22] covers a broad range of communication and special education needs, being tools widely used among special educators and speech-language pathologists. It consists of 3 software products: Boardmaker Plus!, which "turns the computer into a student learning tool allowing teachers to create engaging activities that make learning fun", giving voice, sound, animation and video capabilities; Boardmaker with Speaking Dynamically Pro, with additional features like "natural-sounding voices, word prediction and abbreviation expansion to support augmentative and alternative communication"; and the simplest Boardmaker, allowing the creation of printed materials using Picture Communication Symbols (PCS) and other pictures and graphics.

\section{Kidspiration}

Kidspiration [23] is a tool for K-5 learners for developing thinking skills/literacy, strengthening word recognition, vocabulary, comprehension and written expression as well as building conceptual understanding in mathematics. It is based on visual tools to help combining pictures, text, numbers and spoken words - visual learning. It offers a graphic organizer to help students to express thoughts and explore ideas and relationships. Therefore, by using webs, concept maps and Venn diagrams students clarify thoughts, organize information, apply new knowledge and build critical thinking skills.

\section{Aurora Suite 2005}

Aurora Suite 2005 [24] is "affordable, effective, assistance for augmentative communication, learning disability and dyslexia". It consists of a text-to-speech component (Aurora Echo) which, apart from the text in a document or that on a webpage or another digital document, also converts menus, dialog boxes etc. into text. The second part, Aurora's word prediction "helps with spelling, word choice and sentence construction". While a text is being written, "it applies advanced word prediction, grammatical, and phonetic algorithms to complete words and predict future words". Furthermore, by means of a talking spellchecker common mistakes can be corrected automatically, and in this way the accuracy of the writing can be checked. Finally, Aurora Talk facilitates communication by enabling for the message to be uttered to be first writ- ten, and consequently converted into speech by using a speech synthesizer.

\section{E. Učimo slušati (Let's Learn to Listen)}

Učimo slušati (Let's Learn to Listen) [25] is the first Croatian software package for auditory training of all preand early-school children. It can be used as an educational game or a didactic aid in rehabilitation of children with developmental disorders (children with a Cochlear implant, hearing impairment, poor phonetic perception and auditory discrimination, as well as attention, concentration and auditory perception deficit).

The package is based on 100 different sounds and images which can be used in creating exercises with various options and levels of complexity. There is an option for assessment and evaluation of the therapy which can be conducted by keeping a record of software users and performed exercises, and the assessment of the performance in a particular exercise. Furthermore, it is possible to generate reports, test results or a review upon completing the exercise, as well as conduct the user's (i.e. child's) auditory analysis.

\section{CONCLUSION}

Using computers and specialized software is gaining increasing importance in the process of educating persons with developmental disorders. Although benefits of using computers in such a specific type of education are evident and definitely speak in favour of such practice, this opportunity presents problems for teachers, as they are often "not knowledgeable on how to use these aids" [26].

One of potential difficulties for teachers is the resistance toward introducing new technologies into the educational process, which itself is complex enough. Therefore additional training of both teachers and parents is needed in the field of using ICT. In its application, special attention should be given to meeting pedagogical and psychological standards.

Another potential difficulty may be the software adapted for persons with developmental disorders. Although there is a wide range of educational software products suitable for such education in the market, the usability of such software is still questionable. This can be supported by the specific difficulties witnessed by special teachers using computers in education of children with developmental disorders. Namely, among major disadvantages of the software they used most teachers point out the relatively low software usability ratings. It is therefore recommended that usability evaluations should be introduced for software packages used in instruction. This may enable a larger number of teachers to use the contemporary computer technology in education [27].

Owing to a distinct nature of education of persons with developmental disorders and specificities of curricula such education rests upon, as well as their requirements, additional research into the area of using ICT in such educational contexts is needed. Furthermore, additional training on this specific use of ICT needs to be provided for teachers and parents involved in the education of children with developmental disorders. 


\section{REFERENCES}

[1] World Health Organization, International Classification of Diseases, Injuries and Causes of Death, $2^{\text {nd }}$ edition $-9^{\text {th }}$ revision from 1975 (Međunarodna klasifikacija bolesti, povreda i uzroka smrti, 2. izdanje prema 9. reviziji iz 1975. god.), NIRO "Književne novine", Beograd, 1989.

[2] American Psychiatric Association, Diagnostic and Statistical Manual of Mental Disorders, Fourth Edition (DSM-IV), 2009. http://allpsych.com/disorders/dsm.html (Jan., 15 ${ }^{\text {th }}$ 2009)

[3] M.L. Wehmeyer, G.D. Lance and S. Bashinski, "Promoting access to the general curriculum for students with mental retardation: A multi-level model", Education and Training in Mental Retardation and Developmental Disabilities, vol. 37, no. 3, p. 223-234, 2002. http://www.beachcenter.org/Research\%5CFullArticles $\% 5$ CPDF $\% 5$ CACG2 Promoting $\% 20$ access $\% 20$ to $\% 20$ the $\% 20$ GC. pdf (Dec., 14 $\left.{ }^{\text {th }} 2008\right)$

[4] IDEA 2004, Individuals with Disabilities Education Improvement Act of 2004, http://idea.ed.gov/download/statute.html (Feb., $1^{\text {st }}$ 2009)

[5] NCRL - North Central Regional Educational Laboratory, Assistive Technology to Meet K-12 Student Needs, http://www.ncrel.org/ sdrs/areas/issues/methods/technlgy/te 7assist.htm (Feb., $1^{\text {st }}$ 2009)

[6] B. Means (ed.), Technology and Education Reform: The Reality Behind the Promise, San Francisco, CA: Jossey-Bass., 1994.

[7] L. Florian, "Uses Of Technology That Support Pupils With Special Educational Needs" in ICT and Special Educational Needs, A Tool for Inclusion, (ed. Lani Florian and John Hegarty), McGrawHill International, 2004., http://www.mcgraw-hill.co.uk/ openup/chapters/033521195X.pdf (Feb., $1^{\text {st }}$ 2009)

[8] N.H. Huguenin, "Assessing visual attention in young children and adolescents with severe mental retardation utilizing conditionaldiscrimination tasks and multiple testing procedures", Research in Developmental Disabilities, vol. 25, no. 2, p. 155-181, 2004. (doi:10.1016/j.ridd.2004.01.001)

[9] W.V. Dube and W.J. McIlvane, "Behavioural Momentum In Computer-Presented Discriminations In Individuals With Severe Mental Retardation", Journal of the Experimental Analysis of Behavior, vol. 75, no. 1, p. 15-23, 2001. http://seab.envmed. rochester.edu/jeab/articles/2001/jeab-75-01-0015.pdf (Dec., $14^{\text {th }}$ 2008)

[10] H. Shimizu, J.S. Twyman and J. Yamamoto, "Computer-based sorting-to-matching in identity matching for young children with developmental disabilities", Research in Developmental Disabilities, vol. 24, no. 3, p. 183-194, 2003. (doi:10.1016/S08914222(03)00028-3)

[11] T.S. Tan and W.S. Cheung, "Effects of computer collaborative group work on peer acceptance of a junior pupil with attention deficit hyperactivity disorder (ADHD)", Computers \& Education, vol. 50, no. 3, p. 725-741, 2008. (doi:10.1016/j.compedu. 2006.08.005)

[12] J. Moreno and D. Saldaña, "Use of a computer-assisted program to improve metacognition in persons with severe intellectual disabilities", Research in Developmental Disabilities, vol. 26, no. 4, p. 341-357, 2005. (doi:10.1016/j.ridd.2004.07.005)

[13] P. Standen and D. Brown, "Virtual Reality in the Rehabilitation of People with Intellectual Disabilities: Review", CyberPsychology \& Behaviour, vol. 8, no. 3, p. 272-282, 2005.

[14] D.K. Davies, S.E. Stock and M.L. Wehmeyer, "Application of computer simulation to teach ATM access to individuals with intellectual disabilities", Education and Training in Developmental Disabilities, vol. 38, no. 4, p. 451-456, 2003.

[15] E. Segers and L. Verhoeven, "Long-term effects of computer training of phonological awareness in kindergarten", Journal of Computer Assisted Learning, vol. 21, issue 1, p.17-27, 2005. (doi:10.1111/j.1365-2729.2005.00107.x)
[16] P. Macaruso, P.E. Hook and R. McCabe, "The efficacy of computer-based supplementary phonics programs for advancing reading skills in at-risk elementary students", Journal of Research in Reading, vol. 29, issue 2, p. 162-172, 2006. (doi:10.1111/j.14679817.2006.00282.x)

[17] Y. Lee and C.O. Vail, "Computer-based reading instruction for young children with disabilities", Journal of Special Education Technology, vol. 20, no.1, p. 5-18, 2005. http://jset.unlv.edu/20/ JSETv20n1.pdf (Sep., 25 ${ }^{\text {th }}$ 2008)

[18] R.D. Howell, K. Erickson, C. Stanger and J.E. Wheaton, "Evaluation of a computer-based program on the reading performance of first grade students with potential for reading failure", Journal of Special Education Technology, vol. 15, No. 4, p. 1-13, 2000. http://www.intellimathics.com/pdf/research/Rese arch Literacy.pdf (Sep., $25^{\text {th }} 2008$ )

[19] T.L. Blankenship, K.M. Ayres and J. Langone, "Effects of Computer-Based Cognitive Mapping on Reading Comprehension for Students with Emotional Behaviour Disorders", Journal of Special Education Technology, vol. 20, no.2, p. 15-23, 2005. http://jset.unlv.edu/20/JSETv20n2.pdf\#page=16 (Feb., $1^{\text {st }}$ 2009)

[20] P. Mirenda and K. Turoldo, "The Impact of Word Prediction Software on the Written Output of Students with Physical Disabilities", Journal of Special Education Technology, vol. 21, no.1, p. 5-12, 2006. http://jset.unlv.edu/20/JSETv21n3.pdf\#page $=6$ (Feb., $\left.1^{\text {st }} 2009\right)$

[21] Widgit, SymWriter, http://www.widgit.com/products/symwriter/ index.htm (Feb., $1^{\text {st }} 2009$ )

[22] Mayer-Johnson, Boardmaker Software Family, http://www.mayerj ohnson.com/MainBoardmaker.aspx?MainCategoryID=5419 (Feb., $1^{\text {st } 2009)}$

[23] Inspiration Software, Kidspiration, http://www.inspiration.com/ Kidspiration (Feb., $1^{\text {st }}$ 2009)

[24] Aurora Systems, Aurora Suite 2005, http://www.aurora-systems. com/ (Feb., $1^{\text {st } 2009)}$

[25] Tara, Let's Learn to Listen, Listening practice software (Učimo slušati, Računalni program za slušne vježbe), http://www.taracentar.hr/slusanje.asp (Feb., $1^{\text {st }}$ 2009)

[26] R. Roper, "Using Technology to Teach Students with Mild Disabilities: Current Trends and Future Technologies", Law \& Disorder, issue I, p. 54-58, 2006.

[27] J. Buzhardt, M. Abbott, C. Greenwood and Y. Tapia, "Usability testing of the classwide peer tutoring-learning management system", Journal of Special Education Technology, vol. 20, no 1, p.19-29, 2005.

\section{AUTHORS}

V. Kirinić is with the Department of Information Systems Development, Faculty of Organization and Informatics, University of Zagreb, Pavlinska 2, Varaždin, HR42000, Croatia (e-mail: valentina.kirinic@foi.hr).

V. Vidaček-Hainš is with the Department of Organization, Faculty of Organization and Informatics, University of Zagreb, Pavlinska 2, Varaždin, HR-42000, Croatia (email: vvidacek@foi.hr).

A. Kovačić is with the Department of Foreign Languages, Faculty of Organization and Informatics, University of Zagreb, Pavlinska 2, Varaždin, HR-42000, Croatia (e-mail: andreja.kovacic@foi.hr).

This article was modified from a presentation at The 32nd International Convention MIPRO on information and communication technology, electronics and microelectronics., in 25-29 May 2009, Opatija, Croatia. Manuscript received, 26 February 2010. Published as resubmitted by the authors 1 st March 2010. 